\title{
Integração e fragmentação na cultura organizacional: Discurso e silêncio em uma empresa de alimentos
}

\author{
Integration and fragmentation in the organirational culture: \\ Discourse and silence in a food company
}

\section{Resumo}

O objetivo dessa pesquisa é analisar as visões de colaboradores de uma empresa a partir das perspectivas culturais de integração, de diferenciação e de fragmentação culturais. A literatura funcionalista defende a integração cultural como meio de garantir resultados instrumentais plenos. Os autores interpretativistas defendem uma condição difusa da cultura organizacional. Neste estudo de caso, estas visões foram confrontadas através de documentos e 27 entrevistas semi estruturadas, tratadas através da análise de conteúdo. Os resultados indicam um contexto de diferenciação e de fragmentação, ainda que os documentos e os relatos de alguns participantes tratem a cultura como algo integrado.
\end{abstract}

Henrique César Muzzio de Paiva Barroso ${ }^{\mathrm{I}}$ Maria Ester de Freitas ${ }^{2}$

Palavras-chave: Cultura Organizacional; Integração; Fragmentação.

\begin{abstract}
The aim of this research is to analyze the opinions of works of a Brazilian company from the cultural perspectives of integration, differentiation and fragmentation cultural. Functionalist literature defends the cultural integration as half to guarantee resulted instrumental full. Other authors argue for a diffuse condition of the organizational culture. In a case study, these perspectives had been collated through documents and of 27 interviews. These interviews had been treated through a content analysis. The results indicate a context of cultural differentiation and fragmentation, despite the documents and the stories of some participants treat the culture as something integrated.
\end{abstract}

Keyword: Organizational Culture; Integration; Fragmentation.

\footnotetext{
1 henrique.muzzio@ufpe.br, Brasil. Professor da Universidade Federal de Pernambuco - UFPE. Doutor em Administração de Empresas pela Fundação Getúlio Vargas - FGV-SP. Av. dos Funcionários, s/n, Cidade Universitária, CEP: 50740-580 Recife, PE - Brasil.

2 ester.freitas@fgv.br, Brasil. Professora Titular da Fundação Getúlio Vargas - FGV-SP. Doutora em Administração de Empresas pela Fundação Getúlio Vargas - FGV-SP. Av. 9 de Julho, 2029, Bela Vista, CEP: 01313-902 - São Paulo, SP Brasil.
}

Recebido em 28.11.2012

Aprovado em 04.03.2013

Revista Administração em Diálogo

ISSN 2178-0080

Programa de Estudos Pós-Graduados em Administração

Pontifícia Universidade Católica de São Paulo 


\section{Introdução}

O objetivo dessa pesquisa é analisar, através de um estudo de caso, as visões de atores organizacionais de uma empresa brasileira do setor alimentício a partir das perspectivas culturais de integração, de diferenciação e de fragmentação culturais (MARTIN, I992). Trata-se de uma empresa (identidade preservada) presente em todo o território nacional que passou por um recente processo de profissionalização, um período normalmente impactante na cultura organizacional. A análise aqui efetuada concentrou-se em três unidades funcionais.

A diversidade é uma condição característica das organizações. Alguns autores (PETER, WATERMAN, I982; WILKINS, OUCHI, I983; KHOJA, MARANVILLE, 2OIO; TOMITÃ et. al., 2OIO) defendem a eliminação dos conflitos e das contradições como forma de construir uma cultura forte. É de se esperar que os dirigentes organizacionais possuam um discurso de uniformidade e de coesão cultural, mas isto é o que evidenciamos na prática?

Muitas vezes, em contraponto ao discurso unificador, estão os ressentimentos, as contradições, as ambivalências e as ambiguidades comuns aos jogos de poder que se estabelecem na vida organizacional (FREITAS, I999), podendo se explicitar através de conflitos abertos, embora, o mais comum, seja a guerra disfarçada, ou mesmo, o silêncio, quando as vozes se calam face à estrutura de poder vigente.

Este é um exemplo das contradições que marcam a cultura organizacional que vem ao longo das últimas décadas, desafiando e instigando pesquisadores de diferentes perspectivas ontológicas e epistemológicas que utilizam variadas metodologias para compreender este vasto campo (SMIRCICH, I983; TSUI, NIFADKAR, OU, 2OO7). Diversidade de abordagens que se verifica também quanto às posturas de pesquisadores, que variam desde o do uso de posições intervencionistas (HOFSTEDE, r980; SCHEIN, 2004), até posições interpretativas e simbólicas (PETTIGREW, I979; PRESTES MOTTA, CALDAS, I997; FREITAS, 2007).

Uma característica que normalmente se atribui à cultura organizacional é a noção de valores compartilhados entre seus membros. Mas esse compartilhamento significa necessariamente uma coesão cultural? Morgan e Ogbonna (2008) argúem que isso é 
uma simplificação que talvez se justifique em virtude da natureza problemática do conceito de cultura organizacional.

Parte da literatura interpreta esse campo sob a perspectiva funcionalista, de ontologia realista e epistemologia positivista que trabalha com a condição de uma racionalidade superior, onde é possível alcançar resultados operacionais plenos a partir de uma visão homogênea da cultura organizacional (WILKINS, OUCHI, I983; BARNEY, I986; SCHEIN, 2004). Em outra visão, a cultura é interpretada com base no paradigma interpretativista, de ontologia nominalista e epistemologia antipositivista, reconhecendo as organizações como espaços heterogêneos (MARTIN, FROST, 2oor; RODRIGUES, 2006; SINGH et al, 2008).

Explorando parte desta diversidade, este trabalho foca a visão oficial da empresa representada por documentos e por depoimentos e o sentimento de parte dos empregados a partir de um estudo na matriz e em duas filiais. Para isso, dividimos este artigo em quatro tópicos, além dessa introdução: a pluralidade e o debate que marcam o campo da cultura organizacional; as especificidades da metodologia que usamos na pesquisa de campo; os achados oriundos de entrevistas e sua análise e as considerações finais.

\section{Pluralidade da Cultura Organizacional e Debates Correntes}

O tema cultura organizacional constitui um domínio tácito, complexo e abstrato. O estilo particular de condução dos negócios, desenvolvidos através das relações sociais entre seus membros e entre a organização e o ambiente, instiga conhecermos como cada organização compartilha as idéias comuns, os significados próprios, os processos de transmissão de valores etc., considerados adequados pelos seus membros para o alcance dos objetivos e para o desenvolvimento organizacional.

O pluralismo do campo pode ser exemplificado a partir da meta-análise de Smircich (1983) que estabeleceu uma distinção a partir de duas vertentes, diferenciadas por concepções ontológicas da realidade social (objetividade e subjetividade) e por concepções da natureza humana (determinística ou voluntarista), em que percebemos claramente a visão dicotômica entre a vertente funcionalista e a interpretativista. Baseada 
nas influências antropológicas e organizacionais, a autora propõe que a cultura pode ser uma característica organizacional ou uma metáfora.

Schein (2004), autor de destaque da corrente funcionalista, conceitua cultura organizacional como um “padrão de pressupostos básicos que um determinado grupo criou, descobriu ou desenvolveu lidando com seus problemas de adaptação externa e integração interna, que funcionaram bem o suficiente para serem considerados válidos e, por isso, serem ensinados aos demais integrantes do grupo como a maneira correta de perceber, pensar e sentir em relação aos problemas” (SCHEIN, 2004, p.I7).

Hofstede (I980) define que a cultura é para a coletividade o que a personalidade é para o indivíduo; uma programação mental que distingue os membros de um grupo. Por outro lado, alguns autores trabalham a conceituação de cultura organizacional sob uma perspectiva interpretativista e simbólica. Pettigrew (I979) afirma ser a cultura organizacional um sistema público e coletivamente aceito de significados operados por um dado grupo em um determinado tempo, em que as organizações podem ser exploradas como um sistema contínuo com passado, presente e futuro.

Neste trabalho, definimos cultura organizacional como uma rede de significações que circulam dentro e fora do espaço organizacional, usadas como instrumento de poder, que são criadas e recriadas nas relações cotidianas, sendo simultaneamente ambíguas e contraditórias, revelando a coesão e a fragmentação organizacionais (MARTIN, I992; FREITAS, 20O7).

Em uma corrente alternativa à dicotomia funcionalista $\mathrm{x}$ interpretativisa, os teóricos críticos (ALVESSON, I987; ADLER, 2007) questionam uma instrumentalização das pessoas e da natureza nas ações organizacionais baseada em preceitos positivistas, incluindo aí as questões culturais. Para Alvesson e Deetz (I998) essa instrumentalização é usada para alcançar resultados previsíveis, medidos através da produtividade e da resolução técnica de problemas, sendo entendida como forma de dominação. Tal perspectiva é vista como dotada de importância para o contexto organizacional diante de sua capacidade de gerar reflexões na geração de teorias úteis ao campo e visões alternativas, tais como o pós-estruturalismo feminino, que denuncia a condição desigual no universo organizacional entre homem e mulher, ou ainda, a análise 
pós-colonialista, que denuncia uma nova forma de exploração das nações desenvolvidas frente às nações em desenvolvimento (CALÁS, SMIRCICH, I999).

As concepções de cultura organizacional estão ancoradas em elementos constitutivos da cultura, sendo consensual tanto a sua existência, quanto a sua significância, variando apenas o grau de importância entre eles, ou mesmo, suas formas de manifestação. Dentre esses elementos estão os valores, os pressupostos, os ritos, os rituais, os artefatos, as crenças etc. Oriundos da concepção antropológica, tais elementos também são úteis no contexto organizacional, pois possibilitam uma sinalização do que é, e do que não é, legitimado ou aceito por um grupo (HOFSTEDE, I980; HOFSTEDE et al., I990; VAN DEN BERG, WILDEROM, 2004).

Apesar do escopo da cultura organizacional ser marcado por uma pluralidade, encontramos algumas especificidades que possuem relativo consenso tanto na literatura de orientação funcionalista, como nos trabalhos de orientação interpretativista, como é o caso de sua natureza simbólica. Nessa ótica, o homem é um criador de símbolos, linguagens, crenças, visões, ideologias, mitos etc., o que permite caracterizar a cultura organizacional como um espaço simbólico (TURNER, I986), fruto de um compartilhamento entre seus membros, galgado em valores que o grupo interpretou como adequado para subsidiar seu comportamento e que são válidos para aquele contexto e tempo específicos (PETTIGREW, I979; TRICE, BEYER, I984; LENARTOWICZ, I999). Sem uma legitimidade, a referência de comportamento estaria comprometida, e as bases de ação grupal que alicerçam o comportamento e as ações nas organizações, estariam ameaçadas.

Se uma das características da cultura é o compartilhamento de valores e crenças, isto significa que a cultura organizacional é necessariamente marcada pelo consenso? A existência de subculturas e as condições ambíguas apontadas na literatura (SACKMANN, I992; MORGAN, OGBONNA, 2008) contradizem essa postura consensual. Martin (I992) propõe a presença de três tipos de caracterização que atuam simultaneamente nas organizações: integração, diferenciação e fragmentação, que estariam associadas, respectivamente, a três tipos de interesse de pesquisa: gerencial, descritivo e crítico. Segundo Mathewa e Ogbonna (2009) essas três perspectivas capturam simultaneamente os aspectos unificados da cultura, os temas subculturais, bem como as contradições na 
vida organizacional. Martin e Frost (2OOI) apresentam as perspectivas da integração, diferenciação e fragmentação como integrantes de um campo naturalmente conflitante, onde cada uma delas busca posição hegemônica na validade de suas características, defendendo suas concepções epistemológicas e metodológicas.

A abordagem de integração está ligada ao referencial gerencial / funcionalista e orienta-se quanto ao consenso no nível organizacional, sendo a cultura vista como homogênea, excluindo-se qualquer possibilidade de ambiguidades. Aqui seria possível se construir uma "cultura forte", suficiente para alcançar resultados operacionais superiores. Essa coesão seria viabilizada pelos líderes organizacionais, com a articulação de valores e de políticas formais disseminadas, através do corpo funcional para alcançar uma coesão cultural (SCHEIN, 2004).

Nessa visão de unidade coletiva, os problemas de adaptação externa estariam associados a adaptações que qualquer sistema deveria manter com um ambiente no qual está inserido em busca de sobrevivência. Além disso, devem ser considerados os meios de se atingir tais objetivos e, ainda, possíveis medidas de verificação e correções em caso de não-cumprimento desses (MARTIN, FROST, 2OOI). Os problemas de integração interna estariam ligados ao estabelecimento de linguagem e categorias conceituais comuns para uma boa comunicação e entendimento do grupo, ao delineamento das fronteiras do grupo e aos critérios de inclusão e exclusão, ao estabelecimento de consenso em torno de questões de poder e status, ao estabelecimento de regras de convivência entre os membros, a um entendimento sobre o que deve ser recompensado e punido, e ao desafio de como lidar com o incontrolável (SCHEIN, 2004).

A perspectiva de diferenciação supõe um consenso no nível de subculturas, ou seja, na organização haveria espaço para várias subculturas, que podem conviver em harmonia, independência ou conflito, o que possibilitaria, por exemplo, análises sobre dinâmicas de poder, desigualdade e dominação nas organizações. Os pesquisadores dessa corrente focam nas inconsistências, na perda de consenso e na descentralização das lideranças com ênfase em várias subunidades, incluindo grupos ou indivíduos (MEYERSON, MARTIN, I987; MARTIN, FROST, 20OI). Os valores e as manifestações podem ser contraditórios e os eventos, como os rituais, podem refletir as contradições entre as regras formais e as normas informais, enfatizando-se mais o contra-senso do que 
o consenso. Em termos culturais, uma organização seria composta por diversas subculturas que compartilhariam alguns elementos integrantes da cultura dominante. Aqui, a mudança cultural é incremental e localizada. De acordo com a perspectiva da diferenciação, a cultura não é coesa, sendo mais uma conexão onde se cruzam influências ambientais que criam um conjunto de subculturas sobrepostas e com fronteiras permeáveis (MARTIN, I992; MARTIN, FROST, 2OOI).

Por fim, a abordagem da fragmentação trabalha com uma visão de falta de consenso, uma multiplicidade de interpretações e foca a diversidade cultural e sua consequente ambiguidade, que é entendida aqui como estado interno que se apresenta como não-claro, inexplicável, ou capaz de possuir dois significados, deixando os indivíduos confusos (MEYERSON, MARTIN, I987).

Para Martin e Frost (200I), os defensores dessa perspectiva acham que as relações entre as manifestações da cultura não são nem muito consistentes, nem muito inconsistentes, ao contrário, são complexas, com muitos elementos de contradição e mesmo de confusão. Em tal posição, o consenso não abrangeria a organização como um todo e nem seria específico de uma subcultura; esse seria transitório e específico a uma determinada questão.

A essência da cultura da fragmentação é a ambiguidade e a falta de consenso. Nela, o poder está dissipado por toda a organização, tanto no nível hierárquico como no nível ambiental. Quanto à mudança cultural, essa seria um fluxo contínuo, deflagrada pelo contexto ou por forças que extrapolam o controle dos indivíduos.

Empiricamente essas três perspectivas foram identificadas, por exemplo, em Mathewa e Ogbonna (2009) que analisam uma organização indiana no setor de tecnologia da informação, sob a perspectiva do envolvimento funcional. Morgan e Ogbonna (2008) investigam profissionais do setor de saúde inglês, revelando os valores e as normas compartilhados, diferenciados por subculturas relacionadas aos participantes, e ainda, as condições ambíguas dentro e entre essas subculturas. Rodrigues (2006) apresenta trabalho empírico longitudinal em uma organização do setor de telecomunicações no Brasil onde tais perspectivas são igualmente identificadas.

O discurso é um meio básico de expressão do indivíduo e é através desse que é construído um sentido social das coisas, dos eventos e das interações sociais. Através da 
construção social da realidade (BERGER, LUCKMANN, 2004), a organização é produzida simultaneamente ao sentido que é produzido pelos sujeitos que a compõe (WEICK, 2OOI).

Esse discurso não é algo isento, ao contrário, está vinculado a uma ideologia que dá sentido à vida do indivíduo e à existência das organizações e que normalmente está vinculado a um discurso dominante, daí a necessidade de irmos além do que foi explicitado. Mas se o discurso delimita uma posição ideológica, o silêncio também revela uma não neutralidade na medida em que permite o acesso à contradição entre o dito e o não-dito. Os anseios não-declarados, as manifestações ocultas ou as negações podem elucidar tanto quanto as opiniões ou as afirmações (FREITAS, I999; SIQUEIRA, 2006).

Os discursos gerenciais normalmente contemplam a cultura organizacional como uma integração de seus membros no qual tentam moldar e disciplinar aquilo que é valorizado ou não. Trabalhos de natureza funcionalista argúem por uma capacidade dos gestores moldarem a cultura organizacional, porém, tal visão tem sido muito criticada por perspectivas interpretativas, que entendem a cultura como algo negociado, onde os funcionários são protagonistas na consolidação dos valores organizacionais, ainda que de forma fragmentada.

\section{Metodologia}

Esta pesquisa, de natureza analítico-descritiva, utilizou como estratégia o estudo de caso (STAKE, 2005) para investigar as complexas conexões entre as práticas em ambientes naturais e levantar algumas questões relacionadas à percepção de aspectos culturais de uma organização, uma matriz e duas de suas filiais.

A pesquisa foi realizada em três unidades da Empresa aqui denominada JKL: a matriz, situada em Fortaleza e duas unidades subsidiárias: nas cidades de São Paulo e de Londrina, Estado do Paraná. O grupo JKL, com mais de oitenta anos de atividade, é oriundo do Estado do Ceará. A pesquisa foi realizada em sua empresa do ramo alimentício. Hoje, a JKL é uma empresa profissionalizada e a família fundadora controla a totalidade de seu Conselho de Administração. A empresa possui unidades em todas as regiões do Brasil. Quanto ao seu corpo funcional, o grupo possuía na época da investigação 2.574 funcionários, distribuídos com a seguinte alocação funcional por área 
de negócio: 303 pessoas na área administrativa, I.649 pessoas na área de operações e 622 pessoas na área comercial.

A coleta de dados foi realizada através de 27 entrevistas semi estruturadas. Os participantes ocupavam quatro níveis hierárquicos (Direção, Gerência, Supervisão e Coordenação), a partir da recomendação de pessoas-chave da organização com o uso da estratégia "bola de neve".

Quanto à caracterização dos sujeitos, 2I dos 27 entrevistados são do sexo masculino. A idade média do conjunto de respondentes é de 39 anos. O tempo de serviço dos participantes variou de o6 meses de empresa nas unidades São Paulo e Londrina, até 25 anos de empresa nas unidades Fortaleza e São Paulo.

Todas as entrevistas, com duração média de uma hora, foram gravadas e posteriormente transcritas com a autorização dos participantes, que foram informados sobre a natureza do estudo e ainda lhes foi garantido o anonimato (FONTANA, FREY, 2005). Os respondentes ocupam cargos em quatro níveis hierárquicos (Coordenação, Supervisão, Gerência, Diretoria), atendendo ao critério de triangulação (PATTON, I990), sendo que a delimitação do número de entrevistados ocorreu pela saturação de informações (BAUER, AARTS, 2OO2).

As informações foram tratadas através da análise de conteúdo, que se constitui de um conjunto de técnicas para análise de comunicação, que se dá por procedimentos sistemáticos e objetivos de descrição do conteúdo de mensagens, com o objetivo de obter indicadores que permitam a inferência de conhecimentos relativos às condições de produção e recepção de mensagens, procurando ir além das mensagens concretas (BARDIN, I977). As entrevistas foram tratadas através das seguintes etapas: I) Préanálise: organização inicial dos dados; leitura superficial do material, conhecimento da estrutura, das narrativas e impressões; 2) Exploração e análise do material: codificação das unidades de registro (tema, documento e personagens); 3) Enumeração: identificação de frequência, intensidade e tamanho dado às unidades de registro; 4) Categorização: significados a partir de categorias temáticas homogêneas entre si e mutuamente excludentes; 5) Interpretação: reflexão para identificar relações, contradições, sentidos etc. 
Foram utilizadas cinco categorias de análise: percepção sobre a empresa; percepção sobre a unidade funcional; admiração pela empresa; comportamento funcional padrão; mudança estratégica e comportamento funcional. Essa última categoria surgiu após a aplicação das entrevistas, em virtude da empresa ter passado por uma reorientação estratégica que implicou em profundas mudanças operacionais e na tentativa de modificar comportamentos funcionais enraizados, trazendo consequências para sua cultura.

\section{Resultados e análise}

A cultura da integração é defendida por autores funcionalistas como meio para alcançar um desempenho superior (PETER, WATERMAN, I982; WILKINS, OUCHI, I983; KHOJA, MARANVILLE, 2OIO; TOMITÃ et al., 2OIO). Na categoria percepção sobre a empresa, esse discurso é propagado inicialmente por gestores superiores e disseminado entre outras lideranças (SCHEIN, 2004). Na JKL, documentos (Código de Ética, Jornal Interno, Manual Interno) e parte dos depoimentos enfatizam a necessidade dessa coesão e de padronização das práticas organizacionais: “Acho que a gente não pode ignorar que as diferenças existem, ela é rica, acho que ela é necessária, mas ao mesmo tempo a gente não pode fazer dela um empecilho para desenvolver os programas, os processos da companhia" (Diretor oI São Paulo). "Se busca ser do mesmo jeito que a matriz, andar do mesmo jeito, manter os padrões de qualidade, de produção da empresa do jeito que eles querem, a matriz impõe que todas as unidades sejam, eu acho que isso é muito claro mesmo sendo regiões diferentes [...] não é porque é regional que eles tem outro perfil não" (Supervisor oi Londrina). "Nós somos o começo, as autorizações, as políticas são escritas aqui, como os processos vão acontecer partem daqui, enquanto que as unidades e as regionais de vendas, são orientadas através dos processos, então elas não têm uma autonomia" (Coordenadora o3 Fortaleza).

A segunda categoria refere-se à percepção do participante sobre a sua unidade funcional específica e o que é valorizado em cada uma delas, permitindo identificar diferenciações subculturais. Os dados expõem uma cultura mais diferenciada e mais fragmentada do que coesa. Apenas o registro de envolvimento do funcionário com a sua 
unidade, mesmo que por uma minoria, foi lembrado nas três unidades analisadas, fato que está relacionado à percepção do entrevistado com o seu comprometimento em alcançar os objetivos organizacionais. Se considerarmos o discurso predominante no universo empresarial funcionalista, que enfatiza a necessidade de comprometimento do empregado para que o mesmo alcance uma posição de destaque, os dados evidenciam uma posição discrepante.

São Paulo é a unidade onde isso é mais evidenciado. Ainda assim, o silêncio de outros não condiz com as pressões a que são submetidos os trabalhadores para se engajarem nos objetivos empresariais. Em Fortaleza e em Londrina esse silêncio é ainda maior. Essas pessoas demonstram não ser de fato comprometidas no cotidiano da JKL? Não se pode afirmar isso, apenas é possível que este não seja um discurso que eles externam no grupo; todavia, é curioso, pois, considera-se desejável um funcionário explicitar que é comprometido para, por exemplo, ganhar aceitação de seus superiores e legitimidade de seu grupo, mas esse silêncio da maioria pode significar uma insatisfação disfarçada de indiferença com a realidade organizacional.

O orgulho em trabalhar na respectiva unidade é outro registro que a maioria dos entrevistados não faz citação. Em São Paulo, seus respondentes se veem como funcionários envolvidos nos objetivos organizacionais, mas não citam que sentem orgulho em trabalhar na empresa quando falam de sua unidade específica, fato que é discrepante com a categoria anterior, quando discorriam da empresa em geral, em que esse orgulho aparece em alguns depoimentos. Podemos especular aqui, uma insatisfação pontual desses respondentes com sua unidade, dado que não há um discurso específico que cite tal fato, mas a ausência de orgulho já nos oferece pistas dessa condição.

Tais dados nos permitem especular que, em geral, os funcionários da JKL não se sentem plenamente valorizados em sua empresa. É razoável supor que há um temor pelo que vem em seguida, diante do que já ocorreu em termos de ruptura, assim como também há um descontentamento por novas relações de poder, ou ainda, que estes funcionários não reconheçam uma mudança significativa na política de gestão de pessoas iniciada pela recém-criada Diretoria de Recursos Humanos como algo que supere uma postura instrumental na gestão de pessoas (ALVESSON, DEETZ, I998; ADLER, 2007). 
Tais percepções parecem contradizer com aquilo que a empresa tem como política oficial para seus colaboradores, expressado em seu documento interno Código de Ética.

Outros exemplos expõem a diferenciação cultural entre as unidades quanto àquilo que é valorizado. No caso de São Paulo, há a exclusividade na citação da busca constante por resultados, fato atribuído por alguns como uma condição do paulistano, que eles não vêem na caracterização dos respondentes das outras unidades:

Aqui a cultura é aquela bem são paulina mesmo, só que a gente sempre está correndo atrás de resultados, correndo pra finalizar os processos de forma mais rápida, mais ágil, tentando da melhor maneira possível também repassar para todas as unidades tudo o que a gente faz aqui, troca idéias com as outras unidades... então a gente tenta ter aquele elo que tem sempre de trazer o apressado, mas com qualidade, então a gente tem aquela cultura mesmo de São Paulo, então tem gente que fica até mais tarde... (Coordenadora o2 São Paulo).

Em Londrina, o que se destaca entre os respondentes, é a preocupação por essa unidade representar uma condição desprivilegiada, tanto operacional, como simbolicamente para a JKL. Por ser a menor planta industrial da empresa, e por possuir reduzida "visibilidade" frente à Fortaleza (matriz) e à São Paulo (maior mercado para a empresa): "essa unidade aqui está em uma busca de autonomia, ela está buscando se afirmar. Então eu vejo assim que é uma unidade que está se consolidando, mas ainda tem muito ainda para acontecer" (Coordenadora 03 Londrina), ou ainda nas palavras do Supervisor 01 Londrina: "é uma unidade pequena que precisa muito de investimentos e que no dia-a-dia você vê que está melhorando". Tais percepções acabam por sintetizar a condição fragilizada dessa unidade e certamente, interferem na postura de seus funcionários, fazendo com que se sintam em uma posição não privilegiada.

A terceira categoria de investigação refere-se à unidade funcional mais admirada e as razões atribuídas para essa escolha. Tal percepção é importante para compreendermos se existe para os respondentes um modelo ideal de empresa. A maioria dos respondentes valoriza, em geral, a idéia de uma referência para as práticas organizacionais, e indica uma unidade ideal. Estas indicações revelam um quadro heterogêneo, tanto em relação às diferentes unidades investigadas, como em relação aos motivos dessa percepção.

Dentre aqueles que consideram existir uma unidade admirável, a maior parte cita Fortaleza e aponta como motivos: a sua condição de centro de decisão, e 
a presença do fundador, que funciona como um reforço para os valores da JKL (SCHEIN, 2004) e como inspiração para o comportamento pessoal e profissional: "tem todo um simbolismo na unidade, por ser a matriz, a figura do fundador..." (Gerente 04 Fortaleza).

Tem o aspecto de estar próximo ao poder de decisão, e aí eu acho que sim existe uma admiração, uma vontade de estar mais próximo, então a gente percebe que as pessoas querem estar mais próximo aonde é presidido ou se decide as coisas, o que é melhor até para um crescimento profissional, porque aí a dinâmica, as coisas acontecem com mais rapidez, aonde tem um processo de decisão (Coordenador o3 São Paulo).

Se observarmos esses motivos, emergem ao longo das entrevistas contradições entre a realidade vista por alguns integrantes de Fortaleza e aquilo que foi respondido nesse item. A questão da admiração por Fortaleza como centro de decisão, se contradiz com a perda gradativa de poder dessa unidade para São Paulo, que se evidenciou com a nova atuação no mercado varejista de consumo.

Essa valorização de Fortaleza também não deixa de ser contraditória, se considerarmos os resultados dessa unidade vistos anteriormente sobre orgulho em trabalhar ali, dado que uma minoria faz referência a esse registro, e ainda sobre o envolvimento e a valorização do funcionário nessa unidade, que também foram citados por um número reduzido de respondentes. Os dados também se revelam não-conclusivos, se observarmos a perda de poder que essa unidade vem sofrendo para a unidade São Paulo. Essa condição de unidade ideal de Fortaleza é disseminada nas outras unidades, mas é contraditório com aquilo que os funcionários dessa própria unidade dizem (ou deixam de dizer) em muitos momentos. Por outro lado, São Paulo não é vista como uma unidade admirada (recebeu apenas uma citação entre todos os respondentes), fato também incoerente diante de sua condição de centro estratégico e responsável pela liderança no faturamento empresarial.

Nesse momento da pesquisa, emergiu também posições conflituosas entre as unidades investigadas. Alguns participantes expressaram reprovação por atitudes oriundas de outras unidades, o que nos mostra as tensões e contradições que muitas vezes marcam as organizações (MARTIN, FROST, 200I). Essa condição é ilustrada através do depoimento do Gerente o4 Fortaleza, para quem "O que deu certo é mérito nosso (referindo-se a um discurso de um funcionário das filiais sobre as divergências 
sobre as práticas organizacionais), o que deu errado é culpa da matriz!" ou ainda no discurso do Coordenador $\mathrm{O}_{4}$ Fortaleza, quando se refere à unidade São Paulo e afirma que “Tem unidades que pensam que são 'o rei da cocada preta'. Eles pensam que o Brasil todo tem que girar em função de São Paulo". O respondente emite tal opinião quando questiona o fato da unidade paulista querer impor para todas as unidades brasileiras, padrões operacionais que não serviriam para outras realidades. Os dados mostram ainda, a percepção de alguns respondentes de Fortaleza que se sentem desprivilegiados quando alegam que a unidade São Paulo recentemente só realiza a contratação de paulistas: "Se for realmente uma tendéncia e for virar norma com certeza isso pra mim é um fator de desmotivação, de desmotivação e de certo bairrismo regional..." (Supervisor $\mathrm{O} 2$ Fortaleza).

Em outro exemplo, há uma negação por parte de uma respondente de Londrina de colocar Fortaleza como modelo: "Não tem esse negócio de filho preferido. Eu não vejo nem o coorporativo que as pessoas diziam: olha, é o nosso modelo! Eu vejo que em muitas coisas lá no coorporativo é pior do que nas unidades, eu não vejo nenhuma unidade como modelo não, nem a minha. Para mim na verdade é um eterno aprendizado" (Coordenadora o3 Londrina).

A próxima categoria de análise refere-se ao comportamento dos empregados da JKL quanto àquilo que é considerado como uma conduta ideal diante dos valores organizacionais. O registro mais citado foi o respeito pelo companheiro de trabalho, no sentido de não ser tolerado, dentre outras, as agressões verbais, as brincadeiras preconceituosas, ou o assédio moral. Alguns participantes atribuem essa postura ao Presidente da empresa.

A questão ética é um valor muito percebido e a relação das pessoas, a respeitabilidade entre as pessoas independente de seus níveis de hierarquia. Isso é uma preocupação do Presidente da empresa e ele deixa muito claro que dar poder de decisão às pessoas significa ao mesmo tempo em que ela tem o respeito e a confiança da alta gerência e ela também tem a responsabilidade de levar a ética, levar esses conceitos adiante, até o nosso consumidor final (Gerente or São Paulo).

Mas essa condição de respeito e valorização do capital humano encontra críticas entre alguns respondentes: “O capital humano era muito valorizado, mas eu não vejo isso hoje, ele está voltando para o passado" (Coordenadora o3 Londrina). Essa 
fragmentação ainda é relacionada por um respondente, a fatores discriminatórios por parte do setor de Recursos Humanos, o que contradiz com aqueles que colocam o respeito como um valor da empresa e que é definido em seu Código de Ética:

Cada pessoa que está em sua empresa (unidade), ela procura se dissociar assim do todo, isto eu acho que é um defeito que existe ainda aqui, existe certo constrangimento e um distanciamento entre aqueles que fazem as unidades e a holding, é um aspecto negativo, está faltando alguma coisa que volte a uma engrenagem melhor... até o próprio recursos humanos segrega... se ele (diretor) puder discriminar, ele discrimina (Gerente o3 São Paulo).

Registramos ainda que o respeito pelo cliente foi citado por reduzido número de participantes. Se olharmos pelo lado do não-dito, vemos que esses dados mostram-se preocupantes na medida em que a maioria dos respondentes não vê o respeito pelo cliente como algo importante, como um delineador de seu comportamento na JKL. O que pensar quando em uma empresa voltada para o consumo, esse respeito não é um guia para o comportamento do funcionário?

A última categoria analisada é decorrente de uma grande transformação ocorrida nos últimos anos na empresa JKL, a saída do segmento de commodities para o segmento de varejo. Isso significou para os funcionários uma condição simbólica de um novo tempo em que "nasceu uma nova $J K L "$ (Gerente o3 Fortaleza), como ilustra o depoimento a seguir:

A mudança do objetivo da empresa, que era de commodities, para as padarias, entrava pelo quintal das padarias, aqueles sacos de $7 \mathrm{Okg}, 2 \mathrm{o} \mathrm{kg}$, de farinha e passou para o ramo de consumo, passou para o supermercado, a dona de casa pegando um pacotinho, que é para fazer bolo, farinha de $\mathrm{skg}$ e lá para fazer pão. Isso foi uma mudança radical na forma da JKL ser (Gerente or Fortaleza).

Esses dados mostram que a passagem para o mercado de consumo significou mudanças estruturais e novas demandas nos valores da JKL. Do ponto de vista estrutural, a empresa precisou modificar sua linha de montagem, criar novos produtos, novas embalagens, redesenhar suas operações logísticas, reorientar suas ações de marketing, alterar sua comunicação para alcançar seu novo público alvo, criar novas estratégias corporativas, enfim, toda a empresa foi afetada. O discurso é de que tais mudanças significaram simbolicamente uma "nova empresa": "Eu fui contratado para ser um dos agentes de mudanças, essa é a coisa mais prazerosa que a gente consegue enxergar, que é você olhar pra uma companhia há dois anos e você olhar como está hoje, ela é outra 
empresa, eu entrei na JKL, hoje eu estou numa outra empresa não é?’' (Gerente 02 São Paulo).

O depoimento anterior nos oferece uma dimensão dessa mudança, no qual o respondente afirma trabalhar em uma "outra empresa", em virtude das grandes transformações ocorridas em seus processos organizacionais. Essa "nova” JKL surge a partir da mudança de paradigma, onde existiam clientes cativos com garantia de venda em grandes quantidades, emergiu um cenário de vendas por unidades com a presença de vários concorrentes, inclusive grandes empresas multinacionais, o que fez surgir novas necessidades. A principal mudança da JKL foi a mudança de atitude, de posturas e de pessoas não é? (Gerente o2 São Paulo).

Além de intensa, a mudança da JKL ocorreu de forma rápida. Esse episódio contribuiu ainda mais para evidenciar a fragmentação na empresa, ao colocar em choque os valores enraizados da cultura organizacional, e os novos valores que foram disseminados com o recente posicionamento mercadológico.

Naturalmente, as grandes transformações causam resistências nos indivíduos, por dúvidas e desinformações, por receios de perdas de status e até mesmo de demissões (MARTIN, FROST, 2OOI) e não foi diferente nesse caso. Ainda hoje, esse processo não está consolidado, sinais de resistência ainda persistem mesmo com uma clara política de adequação, que constituiu na obrigatoriedade de enquadramento aos novos valores e que, em muitos momentos, a negação significou o desligamento funcional.

Essa demissão é simbólica (TURNER, I986) em dois sentidos: primeiro serviu como mecanismo de modelo de competência do quadro funcional, com a contratação de pessoas com experiência no segmento de consumo de alimentos e o desligamento daqueles profissionais que, na avaliação dos dirigentes, não tinham aptidão para esse mercado. Segundo, foi usada como forma de pressão para legitimar a chamada "nova" cultura organizacional, através do enquadramento dos colaboradores a uma nova ordem: "Você tem muitas pessoas que entendem e que continuam aí com o processo e tem muitas pessoas que infelizmente não é que são ruins ou que são boas, são pessoas que tem outra cultura enraizada e aí a gente tem que trocar peças, não é?’' (Gerente 02 São Paulo). 
Foi uma mudança completa de gestão da empresa. A empresa precisou abrir mão de bons profissionais que no passado construíram essa empresa e que não estavam preparados do ponto de vista cultural para um mercado de consumo [...] não só precisou mudar processos, mas as pessoas que conduziriam os processos, que foi visto que haveria uma resistência cultural dessas pessoas para essa nova (realidade). (Gerente oI São Paulo).

Criou-se uma dicotomia que simboliza a ruptura de paradigma: a "velha" e a "nova" JKL, onde a criação de sentido (WEICK, 2OOI) dos contratados pósreorientação estratégica em muito difere daqueles empregados mais antigos. Esse novo paradigma significa uma tentativa de impor a esses colaboradores um novo comportamento: "É uma cultura nova, um ritmo novo, para quem está entrando não vejo assim tanta dificuldade, agora para quem já está a mais tempo no grupo eu vejo assim que pode estar formando sim um pouco de choque com o que tinha antes" (Coordenadora O2 Londrina). A resistência à mudança, os novos contratados, as demissões, os novos processos e as novas exigências comportamentais favoreceram uma maior tensão no grupo, o fortalecimento de subgrupos, os ressentimentos entre os antigos colaboradores etc., fatos que acabam por fortalecer a diferenciação e a fragmentação culturais.

Os novos integrantes contratados pela empresa trouxeram suas experiências e não tinham um comprometimento com a cultura até então vigente. Naturalmente que a contratação desse perfil acabou causando choques entre os valores tradicionais da JKL e os novos valores representados pelos recém-contratados. Estes passaram a liderar o processo de mudança para o segmento de consumo e as discordâncias entre as unidades ampliaram-se.

Porém, as ações de uniformização se mostraram insuficientes diante das requeridas transformações significativas na cultura no curto prazo, pois a cultura tradicional da empresa ainda se faz presente no sentido (WEICK, 2OOI) dos empregados mais antigos, nos processos organizacionais, nas estórias, ou seja, no simbólico (TURNER, I986), que não é facilmente transformado como defende a literatura funcionalista (KHOJA, MARANVILLE, 2OIO) e deseja parte significativa dos dirigentes empresariais. Nesse sentido, não é de se estranhar, a despeito da presença de elementos de integração cultural, o aparecimento de dissidências, de ressentimentos, da sensação de perda, das ambiguidades, de paradoxos, enfim, da diferenciação e da fragmentação que visualizamos entre os respondentes dentro das unidades e entre as unidades: 
A gente teve muita mudança em dois anos de forma geral em todo o quadro então isso acaba... você não tem um pessoal é... um vínculo mesmo que cria aquele interesse, vista a camisa da empresa, que trabalhe com um pouco mais de amor por aquilo que faz, com gosto, o pessoal acaba não criando muito vínculo, então eu acho que essa movimentação excessiva acaba complicando um pouco você até conseguir desenvolver um trabalho (Coordenador o5 Londrina).

Esses dados demonstram condições diferenciadas na postura organizacional, ainda que a homogeneidade seja uma proposta organizacional. Há também um sentimento de alguns respondentes que esta profunda e rápida transformação chega a colocá-los como "órfãos de liderança":

A gente precisa de um dono, hoje não tem um dono nessa empresa. Porque existe uma rotatividade grande na empresa de gerente, de diretória, diretória nova. Gerente recém-contratado e as pessoas chegam. Acontece tão rápido que às vezes a gente fica sabendo das coisas. Então assim a comunicação ficou falha, eu vejo a comunicação assim falha pela rapidez das mudanças (Coordenadora o3 Londrina).

Simbolicamente, a opinião de que é preciso um “dono” expõe uma dificuldade da respondente em ver um sentido (WEICK, 2OOI) nas ações organizacionais, pois as referências são difusas e inconsistentes. Uma condição que certamente não é a das mais propícias para consolidar uma integração cultural, ao contrário, mais favorece a um quadro de fragmentação da cultura organizacional.

\section{Considerações Finais}

Na disputa que se estabeleceu pelo domínio no campo da cultura organizacional (MARTIN, FROST, 20OI), há aqueles que partilham uma visão instrumental da cultura, na qual essa pode ser manipulada para maximizar os resultados (KHOJA, MARANVILLE, 2OIO; TOMITÃ Et. Al., 2OIO), por outro lado, há outros que entendem que a mesma não pode ser gerenciada ao ponto de controle. Por exemplo, em um processo de mudança, se faz necessário a existência de negociações e de tempo de maturação das novas idéias. Achados empíricos têm ajudado a consolidar a necessidade de analisarmos a cultura organizacional de forma alternativa, sendo difícil a visão apenas de uniformidade cultural que muitos gestores procuram construir, como se tal igualdade significasse necessariamente algo mais apropriado para as organizações.

É dentro dessa perspectiva que situamos a JKL. Se por um lado há uma busca oficial por uma integridade cultural encontrada em documentos e em determinados 
depoimentos, as percepções de outros participantes mostram que essa integração existe apenas em parte, pois as subculturas e as fragmentações emergem nos depoimentos de seus integrantes. A literatura funcionalista defende a coesão cultural organizacional como meio de garantir uma efetividade instrumental, mas será que as organizações são tão coesas assim? Martin e Frost (2OOI) defendem a existência simultânea da integração, da diferenciação e da fragmentação na cultura das organizações.

Viu-se que a JKL deseja construir uma cultura homogênea em todas as suas unidades através da disseminação de valores e práticas vistos como necessários e imprescindíveis para o alcance dos novos objetivos da organização. Essa política é operacionalizada a partir da reprodução das práticas e dos valores da matriz para as subsidiárias, tendo como propósito a construção de uma cultura harmoniosa que facilite a disseminação das técnicas e das idéias dos dirigentes para as diversas unidades funcionais, bem como a ampliação do controle organizacional. Mas, no caso da JKL, os depoimentos corroboram com as perspectivas da literatura (MARTIN, FROST, 2OOI; MATHEWA, OGBONNA, 2009) sobre a presença também da diferenciação e da fragmentação culturais.

Por fim, podemos dizer que a coesão organizacional é um mito quando ela é vista como sinônimo de uniformidade e homogeneidade. Se há um discurso genérico proferido por dirigentes das organizações que as relevam como dotadas de elementos racionais, que as transformam em eficientes máquinas administrativas, é verdade também que dessas organizações fazem parte indivíduos com sentimentos, valores e visões de mundo que limitam a idéia de racionalidade plena, de total utilitarismo dos recursos humanos e de culto inquestionável a excelência e a coesão social. O caso da JKL nos mostra a contradição entre a visão de alguns líderes por uma cultura homogênea e a visão fragmentada e reativa de parte dos funcionários, não sendo simples a convergência entre essas duas posições.

\section{Referências}

ADLER, P. S. The Future of Critical Management Studies: A Paleo-Marxist Critique of Labour Process Theory. Organization Studies, 28(9), I3I3-1345, 2007.

ALVESSON, M. Organizations, Culture, and Ideology. International Studies of Management \& Organization, I7(3), O4-18, I987. 
ALVESSON, M.; DEETZ, S. Teoria Crítica e Abordagens Pós-Modernas para Estudos Organizacionais. In: CLEGG, S.; HARDY, C.; NORD, W (Org.) Handbook de Estudos Organizacionais v. I: modelos de análise e novas questões organizacionais. São Paulo: Atlas, p. 227266, 1998 .

BARDIN, L. Análise de Conteúdo. Lisboa: Edições 7o, I977.

BARNEY, J. B. Organizational Culture: can it be a source of sustained competitive advantage? Academy of Management Review, $\mathrm{II}(3), 656-665$, 1986.

BAUER, M. W.; AARTS, B. A Construção do Corpus: um princípio para a coleta de dados qualitativos. In: BAUER, M. W.; GASKELL, G. (Org.) Pesquisa qualitativa com texto, imagem e som: um manual prático. Petrópolis: Vozes, . p. 39-63, 2002.

BERGER, P.; LUCKMANN, T. A Construção Social da Realidade. 24. ed. Petrópolis: Ed. Vozes, 2004.

CALÁS, M. B.; SMIRCICH, L. Past Postmodernism? reflections and tentative directions. Academy of Management Review, 24(4), 649-671, I999.

DURIAU, V. J., REGER, R. K., PFARRER, M. D. A content Analysis of the Content Analysis Literature in Organization Studies: research themes, data sources and methodological refinements. Organizational Research Methods, IO(I), 05-34, 2007.

FONTANA, A.; FREY, J. H. The Interview: from neutral stance to political involvement. In: DENZIN, N. K.; LINCOLN, Y. S. (Eds.). Handbook of Qualitative Research. 3. ed. Thousand Oaks: Sage, p. $695-727,2005$.

FREITAS, M. E. Cultura organizacional-identidade, sedução, carisma. Rio de Janeiro: Editora FGV, I999.

Cultura Organizacional: Evolução e Crítica. São Paulo: Thomson Learning, 2007.

HOFSTEDE, G. Cultures Consequences: international differences in work-related values. Beverly Hills: Sage, I980. Identifying Organizational Subcultures: an empirical approach. Journal of Management Studies, 35(I), OI-I2, 1998.

HOFSTEDE, G.; NEUIJEN, B.; OHAYV, D. D.; SANDERS, G. Measuring Organizational Cultures: a qualitative and quantitative study across twenty cases. Administrative Science Quarterly, 35(2), 286316, I990.

KHOJA, F.; MARANVILLE, S. How Do Firms Nurture Absorptive Capacity? Journal of Managerial Issues, 22(2), 262-278, 2010.

LENARTOWICZ, T. Framework for Culture Assessment. Journal of International Business Studies, 3О(4), 78I-I98, I999.

MARTIN, J.; FROST, P. Jogos de Guerra da Cultura Organizacional: a luta pelo domínio intelectual. In: CLEGG, S.; HARDY, C. E.; NORD, W. (Org.) Handbook de Estudos Organizacionais v. 2: reflexões e novas direções. São Paulo: Atlas, p. 2I9-25I, 200 I.

MARTIN, J. Culture in Organizations: three perspectives. New York: Oxford University Press, I992. 
MARTIN, J. Organizational Culture: mapping the terrain. Thousand Oaks: Sage Publications, 2002.

MATHEWA, J.; OGBONNA, E. Organisational culture and commitment: a study of an Indian software organization. The International Journal of Human Resource Management, 20(3), 654-675, 2009 .

MEYERSON, D. MARTIN, J. Cultural Change: an integration of three different views. Journal of Management Studies, 24(6), 623-646, 1987.

MORGAN, P. I. OBBONNA, E. Subcultural Dynamics in Transformation: a multi-perspective study of healthcare professionals. Human Relations, 6I(I), 39-65, 2008.

PATTON, M. Q., Qualitative Evaluation and Research Methods. 2. ed. Newbury Park, CA: Sage, I990.

PETERS, T. WATERMAN Jr., R. In Search of Excellence. New York: Harper Row, I982.

PETTIGREW, A. M. On Studying Organizational Cultures. Administrative Science Quarterly, 24(4), $57^{\mathrm{O}} 5^{8 \mathrm{I}}, \mathrm{I} 979$.

PRESTES MOTTA, F. C; CALDAS, M. P. Introdução: Cultura Organizacional e Cultura Brasileira. In: ______. (Org.) Cultura Organizacional e Cultura Brasileira. São Paulo: Atlas. p. I5-2I, I997.

Rodrigues, S. B. The Political Dynamics of Organizational Culture in an Institutionalized Environment. Organization Studies, 27(4), 537-557 2006.

SACKMANN, S. A. Culture and subculture: An analysis of organizational knowledge. Administrative Science Quarterly, 37(I), I4O-I6I, I992.

SCHEIN, E. H. Organizational Culture and Leadership. 3. ed. San Francisco: Jossey-Bass, 2004.

SINGH, S. K.; SRINIVASAN, V.; SISTA, S.; PARASHAR, M. Cross Cultural Conceptualisations: a case for multiple national cultures in India. Indian Institute of Management Bangalore Management Review, 20(3), 249-262, 2008.

SIQUEIRA, M. V. S. Gestão de Pessoas e Discurso Organizacional. Goiânia: Ed. da Universidade Católica de Goiás, 2006.

SMIRCICH, L. Concepts of Culture and Organizational Analysis. Administrative Science Quarterly, 28(3), 339-358, 1983 .

STAKE, R. E. Qualitative Case Studies. In: DENZIN, N. K.; LINCOLN, Y. S. (Eds.). The Sage Handbook of Qualitative Research. 3. ed. Thousand Oaks: Sage, p. 443-466, 2005.

TOMITÃ, V.; STUPARU, D.; TANCIU, M.; DANIASA, C. The Effect of Organizational Culture on Quality Management Practices. Economics, Management, and Financial Markets, 5(2), 304-309, $20 \mathrm{IO}$.

TRICE, H. M., BEYER, J. M. Studying Organizational Cultures through Rites and Ceremonials. Academy of Management Review, 9(4), 653-669, I984.

TSUI, A. S.; NIFADKAR, S. S.; OU, A. Y. Cross-National, Cross-Cultural Organizational Behavior Research: advances, gaps, and recommendations. Journal of Management, 33(3), 426-478, 2007.

TURNER, B. A. Sociological Aspects of Organizational Symbolism. Organization Studies, 7(2), IOIII5, I986. 
VAN DEN BERG, P. T.; WILDEROM, C. P. M. Defining, Measuring, and Comparing Organisational Cultures. Applied Psychology: An International Review, 53(4), 57O-582, 2004.

WEICK, K. E. Making Sense of the Organization. Oxford: Blackwell Publishing, 2 OoI.

WILKINS, A. L.; OUCHI, W. G. Efficient Cultures: exploring the relationship between culture and organizational performance. Administrative Science Quarterly, 28(3), 468-48I, I983. 